\title{
Treatment evaluation, follow-up and familial screening of medullary thyroid carcinoma by highly specific calcitonin measurements
}

\begin{abstract}
Ainahi $\mathbf{A}$, Kebbou $\mathbf{M}^{\star}$, Timinouni $\mathbf{M}^{\star \star}$, Benabdeljalil $\mathbf{N}^{\star \star \star}$, Oufara $\mathbf{S}$
Laboratoire de Physiologie et Pharmacologie «UFREnvironnement et Santé» FST, Université Hassan II- Mohammdia, Morocco, *Service de Médecine Nucléaire, CHU lbn Rochd, Faculté de Médecine et de Pharmacie, Morocco, ${ }^{* *}$ Laboratoire de Microbiologie et Biologie Moléculaire, Institut Pasteur du Maroc, Morocco, ${ }^{* *}$ Laboratoire d'Hormonologie et Marqueurs tumoraux, Institut Pasteur du Maroc, Morocco
\end{abstract}

Correspondence to: Dr. Abdelhakim Ainahi, E-mail: abdelhakim.ainahi@pasteur.ma

\section{Abstract}

BACKGROUND: Calcitonin is the most sensitive and specific marker for medullary thyroid carcinoma (MTC). AIMS: The aim of this study was to emphasize the role and the limits of plasma basal calcitonin (bCT) measurement in the management of Moroccan MTC patients and their relatives. SETTINGS AND DESIGN: This is a retrospective study on 6 MTC patients referred to our institute from January 1996 to December 2004. MATERIALS AND METHODS: Serum bCT levels were measured in 36 individuals comprising six known MTC cases, 18 relatives and 12 healthy volunteers, using two-sites immunoradiometric assay method. Five of MTC patients have been followed from 12 to 96 months after surgery. STATISTICAL ANALYSIS USED: Calculations were performed using SPSS 10.0 program. Data comparison was done by Student's $t$-test. RESULTS: The circulating preoperative bCT concentrations were elevated for all MTC patients (range, 44,8 -2055 pg/ml, normal < 10). Recent postoperative bCT determinations varied from 24.4 to $1972 \mathrm{pg} / \mathrm{ml}$ in four patients. In one patient, the bCT value decreased to an undetectable level during a follow-up of 12 months. The mean bCT level of relatives was $4.90 \pm 3.54 \mathrm{pg} / \mathrm{ml}$; two patients had slightly elevated bCT. Five (42\%) healthy volunteers had undetectable bCT levels and all had less than $10 \mathrm{pg} / \mathrm{ml}$; the mean bCT value was $3.06 \pm 2.51 \mathrm{pg} / \mathrm{ml}$. CONCLUSIONS: Routine plasma bCT measurement still has an important place in the preoperative diagnosis and follow-up treatment of MTC.

Key words: Calcitonin, medullary thyroid carcinoma, prognostic, calcitonin/blood, humans.

Medullary thyroid carcinoma (MTC) occurs in both sporadic and familial forms. ${ }^{[1]}$ The former may be detected by familial screening using molecular genetic studies of the gene RET, together with basal and pentagastrin-stimulated calcitonin measurements. ${ }^{[1,2]}$ These procedures allow early diagnosis of MTC and lead to early radical surgery, resulting in very high cure rates. ${ }^{[3]}$ On the contrary, sporadic MTC is usually diagnosed after surgery and have few chances of definitive cure. ${ }^{[4]}$

The role and the limits of serum basal calcitonin (bCT) measurement for management MTC patients and their relatives, have been already discussed in relevant literature. To our knowledge, there is no publication investigating bCT values in MTC cases from Morocco. Here, we report the result of evaluation of primary surgery, follow-up and family screening, by highly serum bCT specific measurements. Implementation of a RET mutation screening program is going on, to detect subjects at-risk.

\section{Materials and Methods}

This is a retrospective analysis on 6 patients with MTC, referred to our institute over a period of eight years, 
from January 1996 to December 2004. Five of them have been followed from 12 to 96 months after surgery. The study also included 18 relatives of MTC patients and 12 healthy volunteers recruited in Casablanca, from the Outpatients department. All individuals included in the study were fully informed. Inclusion criteria for the study was any patient with MTC. The following diseases that associated with calcitonin disorders were excluded from the study: pernicious anemia, small-cell lung carcinomas, acute and chronic renal insufficiency, hepatic disorders, breast cancer, chronic pulmonary disease and neuroendocrine pancreatic carcinomas. After taking informed consent from the subjects, a proforma was completed for each patient, that included patient age, sex, date of diagnosis, therapeutic modalities, clinical status, previous hormonal investigation and histological findings were recorded. Classification of patients with MTC was done, based on clinical data, according to the international RET mutation consortium definitions. ${ }^{[5]}$ Patients classified as having sporadic MTC, had no history of inherited MTC disease. Whereas, patients with MTC, pheochromocytoma and / or parathyroid adenoma, were classified as multiple endocrine neoplasia type $2 \mathrm{~A}$ (MEN2A). Total thyroidectomy and at least central neck lymph node dissection, were performed for the treatment of MTC. In case of massive lymph node involvement, lymphadenectomy was completed as possible. The pathological material comprised of surgical specimen or paraffin blocks and was histopathologically examined by the pathologist using a standard technique. In patients with high bCT, an extensive search for $\mathrm{C}$ cell hyperplasia or microscopic MTC loci was conducted by immunohistochemical tests, using anti-calcitonin polyclonal anti-bodies. Screening for hyperparathyroidism was determined by measuring serum intact parathormone (1-84 PTH) and total calcium levels. The search for pheochromocytoma was done by measurement of metanephrine and normetanephrine levels in 24 hour urine excretion, in one patient. Serum bCT level was measured by the two-sites IRMA method which is based on the sandwich technique, with two monclonal antibodies, using the ELSA-hCT commercial kit (CIS Bio International, Gif sur yvette, France), specific for the mature calcitonin monomer, without cross reaction with pro-calcitonin. The antibodies recognized the 11-17 and 24-32 regions of the calcitonin molecule. A total of 5 $\mathrm{ml}$ venous blood was drawn from each subject. Serum was obtained by centrifugation at $2000 \mathrm{rpm}$ for 10 minutes. The whole sample was heat-treated 30 minutes at $56^{\circ} \mathrm{C}$, as soon as it was received in the laboratory, divided into aliquots and stored deep frozen $\left(-20^{\circ} \mathrm{C}\right)$. $200 \mu \mathrm{l}$ of standards, control serum and unknown samples were dispensed into appropriately labelled ELSA tubes and $100 \mu \mathrm{l}$ of the monoclonal anti-hCT tracer was added and mixed. Then it was incubated for 20-24 hours at $18-25^{\circ} \mathrm{C}$. After the end of the incubation period, the ELSA tubes were washed with prepared solution. The resultant radioactivity in the test tubes was measured for 1 minute in the channel of gamma scintillation counter, adjusted for ${ }^{125}$ I measurement (PerkinElmer, life sciences, Wallac 1470 WIZARD automatic gamma counter). A standard curve was prepared by plotting the standards cpm, versus their concentrations. The measured values of the control serum and the patients' samples were read off from the standard curve. The detection limit was $2 \mathrm{pg} / \mathrm{ml}$. The intra-assay coefficient of variation was $6.7 \%$ and that of interassay comparison was $7.9 \%$ between 27 and 101 $\mathrm{pg} / \mathrm{ml}$. The normal plasma bCT levels are below $10 \mathrm{pg} /$ $\mathrm{ml}$, according to the procedures of the GETC (French calcitonin tumors study group). Basal CT and carcinoembryonic antigen (CEA) levels were measured after surgery, to detect recurrence of the disease.

\section{Statistical analysis}

Statistical calculations were performed using commercially SPSS software package for windows, version 10.0. Data were expressed in mean values, with two standards deviation (mean $\pm \mathrm{SE}$ ). Correlation between age and bCT was calculated by SPSS program. Student's $t$-test was used to compare mean values of the groups and gender; $P$ value less than 0.05 was accepted as statistically significant.

\section{Results}

The study comprised of a total of 36 moroccan individuals. They were divided into three groups: Group 1 included 6 patients with histologically confirmed MTC, 5 females and 1 male. The age of patients ranged from 18 to 70 years, with mean age of 39.5 years. Of the six MTC patients, 3 (50\%) were diagnosed before the age of 30 years and 2 (34\%) were diagnosed at 31 and 45 years, respectively. 1 (16\%) patient died of disease. Three $(50 \%)$ cases had features of MEN2A phenotype. The remaining cases were considered as sporadic MTC. The clinical presentation of cases with hereditary MTC did not differ from that of patients with sporadic MTC. The hormone evaluation revealed an elevated pre-operative serum bCT concentration and the values were ranged from 44.8 to $2,055 \mathrm{pg} / \mathrm{ml}$ [Table 1]. The mean follow-up at the time of writing this paper, was 58 months (range, 12-96 months). Serum bCT measurements were available for 5 of them after surgery. Postoperative bCT levels were elevated in four patients and the values were between 
Table 1: Summary of laboratory findings

\begin{tabular}{|c|c|c|c|c|c|c|c|}
\hline Patient & $\begin{array}{c}\text { Age } \\
\mathrm{yr}\end{array}$ & Sex & $\begin{array}{l}\mathrm{bCT}^{*} \\
\mu \mathrm{g} / \mathrm{ml} \\
\mathrm{N}<10\end{array}$ & $\begin{array}{c}\mathrm{CEA}^{\dagger} \\
\mu \mathrm{g} / \mathrm{ml} \\
\mathrm{N}<10\end{array}$ & $\begin{array}{c}\mathrm{i}^{\mathrm{P}} \mathrm{TH}^{\dagger} \\
\mu \mathrm{g} / \mathrm{ml} \\
\mathrm{N}, 11 \text { to } 02\end{array}$ & $\begin{array}{c}\text { u-MN§ } \\
\mu g / \text { day } \\
N<340\end{array}$ & $\begin{array}{l}\text { u-NMN" } \\
\text { ug/day } \\
<440\end{array}$ \\
\hline 1 & 70 & M & 1,500 & ND & ND & ND & ND \\
\hline 2 & 52 & $\mathrm{~F}$ & 1,344 & 1.23 & 47.25 & ND & ND \\
\hline 3 & 24 & $F$ & 100 & 2.39 & 73.09 & ND & ND \\
\hline 4 & 23 & $\mathrm{~F}$ & 2,055 & 2.14 & 19.24 & ND & ND \\
\hline 5 & 50 & $F$ & 72.4 & 31 & 5.91 & ND & ND \\
\hline 6 & 18 & $F$ & 44.8 & 1.47 & 31.35 & $>1000$ & $>3000$ \\
\hline
\end{tabular}

${ }^{*}$ bCT: basal calcitomin, ${ }^{\dagger}$ CEA: carcinocmbryonic antigon, ${ }^{\dagger} \mathrm{i}-\mathrm{PTH}$ : intact parathymid hormono, ${ }^{\S} \mathrm{u}-\mathrm{MN}$ : urinary metanephrine; "uNMN: urinary normetanephrine, ND: no determined.

24.4 and 1,972 pg/ml. As shown in Figure 1, plasma bCT levels remained high in two sporadic MTC cases (patients 2 and 5) 96 months after surgery [Figure 1]. One of them had moderately increased CEA and developed lymph node metastases (patient 5) [Table 2]. Whereas, during subsequent follow-up of 12 months, serum bCT was undetectable in one patient MEN2A. This kindred had bilateral foci as histological finding and elevated serum intact PTH (patient 3 ). In the remaining two MEN2A cases (patients 4 and 6), serum bCT levels decreased to 119.86 and

$24.4 \mathrm{pg} / \mathrm{ml}$, respectively [Figure 2]. Group 2 included 18 relatives of subjects in group 1 . They were 8 females and 10 males, the age ranged between 15 and 73 years and the mean age was 42.18 years. Sixteen $(90 \%)$ subjects had normal bCT levels. The mean of plasma bCT concentrations was $4.90 \pm 3.54 \mathrm{pg} / \mathrm{ml}$. Two male subjects had slightly elevated bCT concentrations. The values were $11.23 \mathrm{pg} / \mathrm{ml}$ and $12.36 \mathrm{pg} / \mathrm{ml}$, respectively. The plasma bCT determination showed no correlation with the age

\begin{tabular}{lcccc}
\hline \multicolumn{5}{l}{ Table 2: Summary of clinical data } \\
\hline Patient & $\begin{array}{l}\text { Age } \\
\text { yrs }\end{array}$ & Sex & $\begin{array}{c}\text { Age at } \\
\text { diagnosis of MTC }\end{array}$ & Pathology \\
\hline 1 & 70 & M & ND & MTC* $^{*}$ \\
\hline 2 & 52 & F & 31 & MTC \\
\hline 3 & 24 & F & 17 & Bilateral foci \\
\hline 4 & 23 & F & 22 & of MTC \\
\hline & & & & Bilateral foci \\
\hline 5 & 50 & F & 32 & MTC + thyroiditis \\
\hline 6 & 18 & F & 17 & MTC \\
\hline
\end{tabular}

*MTC: medullary thyroid carcinoma, ND: not determined distribution. But there was a significant difference between bCT values in men and women $(P=0.013$, degree of freedom $=14.95 \%$ confidence interval). Group 3 Twelve healthy subjects without any known thyroid disease, were recruited as controls for this study. They were 9 females and 3 males. The age varied from 22 to 45 years, with mean age of 37.67 years. Five $(42 \%)$ normal subjects had undetectable bCT levels and $100 \%$ of these subjects had a basal level less than 10 $\mathrm{pg} / \mathrm{ml}$. The mean value was $3.06 \pm 2.51 \mathrm{pg} / \mathrm{ml}$. Neither age nor sex was found to have significant correlation with serum bCT. No statistical significant difference between serum bCT levels of relatives as compared to controls, was observed [Table 3].

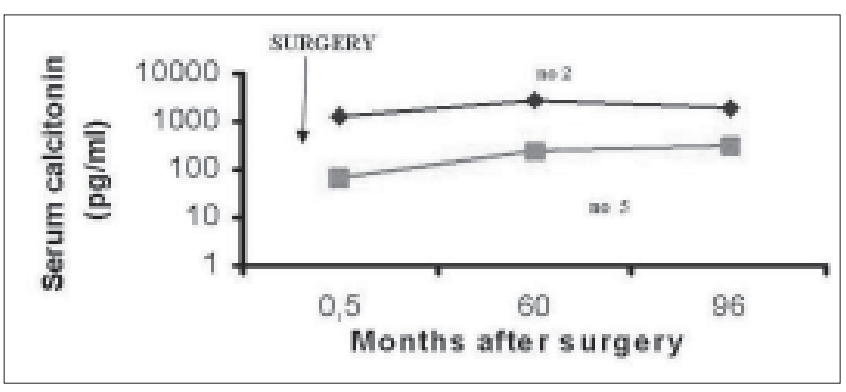

Figure 1: Plasma basal calcitonin concentrations after surgery in the two patients with sporadic medullary thyroid carcinoma. The vertical axis in log scale. no $=$ patient's identification number.

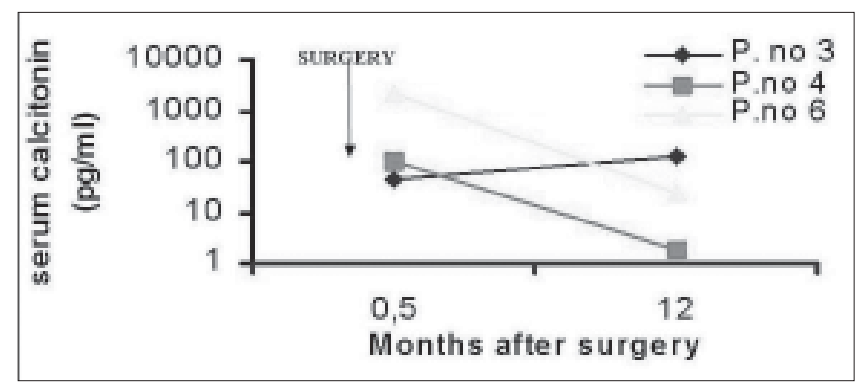

Figure 2: Plasma basal calcitonin concentrations after surgery in the three patients with mutiple endocrine neoplasia type 2A.The vertical axis in log scale. P.no - patient's identification number 2) 
Table 3: Comparison of data

\begin{tabular}{|c|c|c|c|c|c|}
\hline \multirow[t]{2}{*}{ Variable } & \multirow{2}{*}{$\begin{array}{c}\text { Mean of } \\
\mathrm{bCT}^{*} \text { level } \\
(\mu \mathrm{g} / \mathrm{ml})\end{array}$} & \multicolumn{2}{|c|}{$95 \% \mathrm{C}^{\circ} \mathrm{I}^{\dagger}$} & \multirow[t]{2}{*}{$d f^{\S}$} & \multirow{2}{*}{$\begin{array}{c}P \\
\text { value }\end{array}$} \\
\hline & & Lower & Upper & & \\
\hline Controls & $4.90 \pm 3.54$ & & & & \\
\hline Relatives & $3.05 \pm 2.51$ & & & & \\
\hline Controls vs relatives & & -4.302 & 0.640 & 26 & 0.14 \\
\hline \multicolumn{6}{|c|}{$\begin{array}{l}{ }^{*} \text { bCT: based calcitonin levels, }{ }^{\dagger} \mathrm{C} . \mathrm{I} \text {. confidence level, }{ }^{\S} \mathrm{df} \text {. degree of } \\
\text { freedom. }\end{array}$} \\
\hline Discussion & & & & & \\
\hline
\end{tabular}

MTC accounts for approximately $5-10 \%$ of all thyroid malignancies and its prognosis is considerably worse than those of papillary and follicular carcinomas. ${ }^{[6]}$ As in the familial forms, early diagnosis and radical treatment of sporadic MTC may also offer the possibility of obtaining a high cure rate, if bCT measurement becomes a common screening method for nodular thyroid disease. ${ }^{[7]}$

In this retrospective study, we describe the result of bCT measurement in treated MTC cases, as well as their family members and several healthy volunteers. In our series, diagnosis of MTC was confirmed by biochemical screening and both patients with sporadic and familial forms presented elevated bCT levels as described in similar studies, in the literature. ${ }^{[8,9]}$ However, despite total thyroidectomy and careful lymph node dissection in the central neck department, persistent significantly elevated bCT levels were observed in two sporadic MTC cases, suggesting a suspicious residual tissue or recurrent tumor, several years after surgery. In this setting, the literature states that total thyroidectomy with meticulous triple compartment nodal dissection appears to be associated with better prognosis. ${ }^{[10]}$ Whereas, in familial form, bCT concentrations were still abnormal, although reduced in all but one patient. In this case, stimulated calcitonin levels are more sensitive than basal values, to detect the cure. ${ }^{[11,12]}$ Unfortunately, this test was not done in our laboratory, because this study is retrospective and suffers from lack of adequate material. The moderately elevated bCT is very often due to some occult disease, that may have escaped the various imaging modalities. Those patients need life-long follow-up to define extent of any local or distant disease, as early as possible.

On the other hand, it is well known that biochemical cure rates of sporadic MTC are lower than familial MTC. ${ }^{[13]}$ Hence, even the number of patients in our series was too small to draw appropriate conclusions regarding the interpretation of postoperative bCT values and it can be postulated that familial MTC is associated with better outcome. Presumably, due to the inclusion of patients with elevated serum bCT, advanced stage and distant metastasis, our rate of biochemical remission (1/6) was lower than the reported data, with early or prophylactic thyroidectomies following genetic screening for familial disease. This clinical finding do not constitue an evidence and is quite in line with data from literature. ${ }^{[13,14]}$ The definitive cure of the tumor depends upon the stage at diagnosis and the completeness of the initial surgery. As a consequence, it is clear that wide use of bCT in thyroide nodule investigation would lead to early detection of MTC. ${ }^{[14]}$ Unfortunately, in our country, as seen elsewhere, the late diagnosis may be attributed to lack of access to medical facilities and non existent screening programs. ${ }^{[15]}$

Another interesting point is worth emphasizing. The time course of bCT levels, appears to be a potential prognostic marker after surgery. Recently bCT doubling times, but not absolute values, have been described as capable of assessing the risk-level for patients who are not cured by surgical treatement. ${ }^{[16]}$ The lack of data points have ruled out the possibility to extend the present work of studying the kinetics of bCT, in our entire population.

Using bCT measurements in family screening, we failed to detect cases among relatives. Only slightly elevated bCT levels were found in two cases, in our series. Further investigations did not find any clinically detectable MTC localization in those subjects. In one of them, biochemical evidence of Hashimoto's thyroiditis was observed. Unfortunately, false negative as false positive tests may occur with biochemical screening, particularly in the lower range. ${ }^{[2,14,17]}$ Currently, a molecular study is going on for those individuals, seeking the most frequently described mutations of the RET gene. Results of this screening study will be available soon. Finally, MTC is a rare disease and collection of data needs a time. Future clinical research with lengthier follow-up in a larger series, will be needed to verify our observations. Nonetheless, the current study forms the baseline for other investigations on MTC from Morocco in the years to follow and demonstrates that routine plasma bCT measurement still has a very important place in the preoperative diagnosis and follow-up treatment of MTC. For MTC family screening, the bCT concentration is effective, when the levels are clearly high. When the values are low or borderline, results are not sufficient to establish a diagnosis of hereditary MTC. Dynamic investigation, such as pentagastrin-stimulated test and RET gene studies will improve the management of that disease. 


\section{Acknowledgement}

We thank all the families involved in this study and the following Biostatisticians from Faculty of Medicine and Pharmacy, Department of Biostatistic and Epidemiology of Casablanca, Morocco for their collaboration: Prof. Bennani Othmani M and Dr. Nani S. We also thank Prof. Mohammed Hassar, Director of Institut Pasteur du Maroc, for his review and editing the manuscript as well as his help during the study.

\section{References}

1 Tsai MS, Ledger GA, Khosla S, Gharib H, Thibodeau SN. Identification of multiple endocrine neoplasia type 2 gene carriers using linkage analysis and analysis of the ret proto-oncogene. J Clin Endocrinol Metab 1994;78:1261-4.

2 Schuffenecker I, Billaud M, Calender A, Chambe B, Ginet N, Calmettes $\mathrm{C}$, et al. RET proto-oncogene mutations in French MEN 2A and FMTC families. Hum Mol Genet 1994;3:1939-43.

3 Moley JF, DeBenedetti MK, Dilley WG, Tisell LE, Wells SA. Surgical management of patients with persistent or recurrent medullary thyroid cancer. J Intern Med 1998;243:521-6.

$4 \quad$ Hahm JR, Lee MS, Min YK, Lee MK, Kim KW, Nam SJ, et al. Routine measurement of serum calcitonin is useful for early detection of medullary thyroid carcinoma in patients with nodular thyroid diseases. Thyroid 2001;11:73-80.

5 Mulligan LM, Marsh DJ, Robinson BG, Schuffenecker I, Zedenius J, Lips CJ, et al. Genotype-phenotype correlation in multiple endocrine neoplasia type 2: Report of the International RET Mutation Consortium. J Intern Med 1995;238:343-6.

6 Duh QY, Sancho JJ, Greenspan FS, Hunt TK, Galante M, deLorimier $\mathrm{AA}$, et al. Medullary thyroid carcinoma: The need for early diagnosis and total thyroidectomy. Arch Surg 1989;124:1206-10.

7 Vierhapper H, Raber W, Bieglmayer C, Kaserer K, Weinhausl A, Niederle B. Routine measurement of plasma calcitonin in nodular thyroid diseases. J Clin Endocrinol Metab 1997;82:1589-93.
8 Pacini F, Fontanelli M, Fugazzola L, Elisei R, Romei C, Di Coscio $\mathrm{G}$, et al. Routine measurement of serum calcitonin in nodular thyroid diseases allows the preoperative diagnosis of unsuspected sporadic medullary thyroid carcinoma. J Clin Endocrinol Metab 1994;78:826-9.

9 Rieu M, Lame MC, Richard A, Lissak B, Sambort B, Vuong-Ngoc $\mathrm{P}$, et al. Prevalence of sporadic medullary thyroid carcinoma: The importance of routine measurement of serum calcitonin in the diagnostic evaluation of thyroid nodules. Clin Endocrinol (Oxf) 1995;42:453-60.

10 Dorairajan N, Saravanakumar P, Karthikeyan S, Siddharth D, Kanna S. Review analysis of medullary carcinoma thyroid- 15 year Indian experience. J Indian Med Assoc 2005; 103:415-7.

11 Engelbach M, Gorges R, Forst T, Pfutzner A, Dawood R, Heerdt S, et al. Improved diagnostic methods in the follow-up of medullary thyroid carcinoma by highly specific calcitonin measurements. J Clin Endocrinol Metab 2000;85:1890-4.

12 Lips CJ, Hoppener JW, Thijssen JH. Medullary thyroid carcinoma: Role of genetic testing and calcitonin measurement. Ann Clin Biochem 2001;38: 168-79.

13 Niccoli-Sire P, Murat A, Baudin E, Henry JF, Proye C, Bigorgne JC, et al. Early or prophylactic thyroidectomy in MEN 2/FMTC gene carriers: Results in 71 thyroidectomized patients. The French Calcitonin Tumours Study Group (GETC). Eur J Endocrinol 1999; 141:468-74.

14 Elisei R, Bottici V, Luchetti F, Di Coscio G, Romei C, Grasso L, et al. Impact of routine measurement of serum calcitonin on the diagnosis and outcome of medullary thyroid cancer: Experience in 10,864 patients with nodular thyroid disorders. J Clin Endocrinol Metab 2004;89:163-8.

15 Raina V, Bhutani M, Bedi R, Sharma A, Deo SV, Shukla NK, et al. Clinical features and prognostic factors of early breast cancer at a major cancer center in North India. Indian J Cancer 2005;42:40-5.

16 Barbet J, Campion L, Kraeber-Bodere F, Chatal JF. GTE Study Group. Prognostic impact of serum calcitonin and carcinoembryonic antigen doubling-times in patients with medullary thyroid carcinoma. J Clin Endocrinol Metab 2005;90:6077-84.

17 Horvit PK, Gagel RF. The goitrous patient with an elevated serum calcitonin - What to do? J Clin Endocrinol Metab 1997;82:335-7. 